Grand Valley State University

ScholarWorks@GVSU

$12-2008$

\title{
Preliminary Analysis of the Ecology and Geography of the Asian Nuthatches (Aves: Sittidae)
}

Shaily Menon

Grand Valley State University, menons@gvsu.edu

Zafar-UI Islam

National Wildlife Research Center

Jorge Soberon

University of Kansas

A. Townsend Peterson

University of Kansas

Follow this and additional works at: https://scholarworks.gvsu.edu/biopeerpubs

Part of the Biology Commons, Other Ecology and Evolutionary Biology Commons, Poultry or Avian Science Commons, and the Zoology Commons

\section{ScholarWorks Citation}

Menon, Shaily; Islam, Zafar-Ul; Soberon, Jorge; and Peterson, A. Townsend, "Preliminary Analysis of the Ecology and Geography of the Asian Nuthatches (Aves: Sittidae)" (2008). Peer Reviewed Publications. 2. https://scholarworks.gvsu.edu/biopeerpubs/2 


\title{
PRELIMINARY ANALYSIS OF THE ECOLOGY AND GEOGRAPHY OF THE ASIAN NUTHATCHES (AVES: SITTIDAE)
}

\author{
SHAILY MENON, ${ }^{1,5}$ ZAFAR-UL ISLAM, $, 2,4$ JORGE SOBERÓN, ${ }^{3}$ AND \\ A. TOWNSEND PETERSON ${ }^{3}$
}

\begin{abstract}
We explored distributions of Asian nuthatch species in ecological and geographic space using ecological niche modeling based on occurrence data associated with specimens and observations. Nuthatches represent a well-defined clade occurring throughout the Northern Hemisphere, but are most diverse in southern Asia where 15 of the 24 species occur and where the lineage is believed to have evolved. Species richness was focused in a narrow east-west band corresponding to the forested parts of the Himalayas with a maximum number of nine species predicted present in these foci. The distributional predictions have a mid-elevation focus with highest species diversity between 1,000 and 2,000 m. Niche breadth and volume were positively related, but accumulation of distributional area (niche volume) decreased with additional environmental combinations (niche breadth). The extent of potential range filling, a measure of distributional disequilibrium, was connected with montane habit $\left(R^{2}=0.422\right)$ indicating that montane situations limit the distributional potential of species. Received 13 September 2007. Accepted 1 February 2008.
\end{abstract}

The Sittidae consists of 25 species in two genera: Sitta with 24 species (nuthatches) and Tichodroma with a single species (Wallcreeper $[$ T. muraria $])$. The family was conceived much more broadly (Mayr and Amadon 1951) to contain other, superficially similar groups, such as Daphoenositta (the sittellas of New Guinea and Australia), now known to have converged on a similar feeding niche and morphology from different ancestry (Sibley and Ahlquist 1990). True nuthatches occur throughout the Northern Hemisphere, but are most diverse in southern Asia where 15 of the 24 species occur (Harrap and Quinn 1995), and where the lineage probably evolved (Matthysen 1998). The co-occurrence of many closely-related species was noted by Ripley (1959) and Lack (1971). Matthysen (1998) observed that many nuthatch species have small ranges, although 5-7 nuthatch species occur at sites across southeast Asia, generally segregated by elevation, habitat, or both (Lack 1971, Matthyssen 1998).

Nuthatch distributions range from narrow endemism to broad distributions crossing con-

\footnotetext{
${ }^{1}$ Biology Department, Grand Valley State University, Allendale, MI 49401, USA.

${ }^{2}$ Bombay Natural History Society, Mumbai, India.

${ }^{3}$ Natural History Museum and Biodiversity Research Center, University of Kansas, Lawrence, KS 66045, USA.

${ }^{4}$ Current address: National Wildlife Research Center, Taif, Saudi Arabia.

${ }^{5}$ Corresponding author; e-mail: menons@gvsu.edu
}

tinents. For example, the White-browed Nuthatch (Sitta victoriae) is microendemic, restricted to Mount Victoria in western Burma; in contrast, Eurasian Nuthatch (S. europaea) ranges across much of Eurasia. Nuthatches are typical in temperate and subtropical areas of the Northern Hemisphere with two species $(S$. europaea and $S$. canadensis) occurring well into the subarctic, almost to the northern edge of the boreal forest (Matthysen 1998). Fewer nuthatch species occur in tropical regions of southern Asia and only two (S. frontalis and $S$. azurea) reach the Equator.

New informatic approaches offer novel insights into the interaction between ecology and geography in evolving lineages (Soberón and Peterson 2004, 2005). In particular, diverse hypotheses relevant to distributional ecology and biogeography can be tested: conservatism of ecological niche characteristics (Peterson et al. 1999), ecological innovation (Peterson and Holt 2003, Graham et al. 2004), distributional equilibrium with climate features (Svenning and Skov 2004), identification of barriers to dispersal (Peterson 2003), the role of interspecific competition in shaping species' distributions (Anderson et al. 2002), and others. The objective of this paper is to analyze and explore the ecology and distributions of Asian nuthatch species as a first step toward a more integrative view of nuthatch evolution and biogeography.

\section{METHODS}

Data.-We focused on 14 species in the genus Sitta and one species in the genus Ti- 
TABLE 1. Species analyzed and occurrence data available for each. Crude estimates of actual distribution area, potential distribution area, and proportional range filling are included.

\begin{tabular}{llrrrc}
\hline \multicolumn{1}{c}{ Species } & \multicolumn{1}{c}{ Common name } & $\begin{array}{c}\text { Number of } \\
\text { occurrence } \\
\text { points }\end{array}$ & $\begin{array}{c}\text { Actual } \\
\text { distribution } \\
\text { area }\left(\mathrm{km}^{2}\right)\end{array}$ & $\begin{array}{r}\text { Potential } \\
\text { distribution } \\
\text { area }\left(\mathrm{km}^{2}\right)\end{array}$ & $\begin{array}{c}\text { Proportional } \\
\text { range filling }\end{array}$ \\
\hline Sitta cashmirensis & Kashmir Nuthatch & 17 & 5,387 & 21,739 & 0.25 \\
S. castanea & Chestnut-bellied Nuthatch & 69 & 44,362 & 98,433 & 0.45 \\
S. europaea & Eurasian Nuthatch & 40 & 240,678 & 275,212 & 0.87 \\
S. formosa & Beautiful Nuthatch & 63 & 7,800 & 24,618 & 0.32 \\
S. frontalis & Velvet-fronted Nuthatch & 60 & 41,620 & 83,444 & 0.5 \\
S. himalayensis & White-tailed Nuthatch & 27 & 5,829 & 93,258 & 0.06 \\
S. leucopsis & White-cheeked Nuthatch & 23 & 10,212 & 38,181 & 0.27 \\
S. magna & Giant Nuthatch & 45 & 7,448 & 18,345 & 0.41 \\
S. nagaensis & Chestnut-vented Nuthatch & 27 & 9,512 & 41,953 & 0.23 \\
S. solangiae & Yellow-billed Nuthatch & 3 & 77 & 2,171 & 0.04 \\
S. tephronota & Eastern Rock Nuthatch & 34 & 29,776 & 71,930 & 0.41 \\
S. victoriae & White-browed Nuthatch & 2 & 48 & 48 & 1.00 \\
S. villosa & Chinese Nuthatch & 10 & 11,779 & 46,344 & 0.25 \\
S. yunnanensis & Yunnan Nuthatch & 7 & 3,005 & 11,830 & 0.25 \\
Tichodroma muraria & Wallcreeper & 56 & 126,802 & 142,392 & 0.89 \\
\hline
\end{tabular}

chodroma occurring in Eurasia. Occurrence information was accumulated from natural history museums across North America, including the Museum of Comparative Zoology, Field Museum of Natural History, University of Kansas Natural History Museum, and the U.S. National Museum of Natural History; data were also drawn from data bases developed by BirdLife International (Collar et al. 2001). Textual descriptions of occurrence localities were translated into geographic coordinates in decimal degrees using the GeoNet Names Server (National Geospatial Intelligence Agency 2007) and BioGeomancer (Chapman and Wieczorek 2006). The final data set consisted of 483 occurrence points with samples for individual species ranging from 2 to 69 (Table 1). The amount of occurrence data available for Asian nuthatch species was variable. For most species, we had more than sufficient information to characterize ecology and distribution. However, in two or three cases, sample sizes available were marginal (Sitta victoriae, 2 points; S. solangiae, 3 points; S. yunnanensis, 7 points). Some analyses suggest these sample sizes are probably too low (Stockwell and Peterson 2002b), but others indicate that such models may be viable (Peterson et al. 2006). These three species are genuinely microendemics and a few points are likely to be most of what is available, particularly in the single mountain range endemic $S$. victoriae. Our analyses do not in- volve any projections to other time periods or other regions; we believe the effects of the potentially poor fit of these models are slight.

Climate data (1960-1990) were drawn from the WorldClim climate data archive (Hijmans et al. 2005). We used a subset of the 'bioclimatic' coverages: annual mean temperature, mean diurnal temperature range, maximum temperature of warmest month, minimum temperature of coldest month, annual total precipitation, and precipitation of wettest and driest months. We supplemented these data sets with information from the U.S. Department of Interior, Geological Survey's Hydro$1 \mathrm{~K}$ data set (USDI 2001) for topography and landform (slope, aspect, compound topographic index). We resampled all data sets to $0.17^{\circ}$ resolution to avoid over interpretation of the precision of the point-occurrence data.

Ecological Niche Modeling.-We used ecological niche modeling to provide a picture of likely distributional patterns for each species. This general class of procedures is based on known occurrences of species, as they relate to digital raster data coverages that summarize potentially relevant ecological parameters. The goal is to identify a suite of ecological conditions within which the species in question can likely maintain populations without immigration subsidy (Grinnell 1917). The result is a picture of the species' potential geographic distribution, defined as the area meeting the species' ecological niche requirements 
that characterize known distributional areas (Soberón and Peterson 2005). We used the Genetic Algorithm for Rule-set Prediction, or GARP (Stockwell and Peters 1999), which has seen extensive testing and application to such questions (Peterson and Cohoon 1999; Stockwell and Peterson 2003; Stockwell and Peterson 2002a, 2002b). GARP is an evolutionary-computing approach that relates known occurrences of species to raster data layers summarizing relevant environmental parameters to create a model of the ecological niche of the species, which can be used to identify a potential geographic distribution (Soberón and Peterson 2005). We used 19 bioclimatic variables from the WorldClim global $0.17^{\circ}$ data set (Hijmans et al. 2005), plus data on topography and landform including elevation, slope, aspect, and compound topographic index (USDI 2001) to characterize ecological landscapes.

Our use of GARP is for visualization and interpolation purposes only, and the technique has been documented in detail elsewhere (Anderson et al. 2002, 2003; Illoldi et al. 2004; Martínez-Meyer et al. 2004; Ortega-Huerta and Peterson 2004; Soberón and Peterson 2004; Peterson 2005). Thus, we do not provide a full, detailed description. We used half of the available occurrence data for training models, and half to provide test data sets that characterized model success in predicting independent occurrence points. We developed 100 replicate models for each species using GARP and followed recent recommended protocols (Anderson et al. 2003) in using independent measures of omission and commission (Type I and Type II) prediction error to identify an optimal $10 \%$ of models from the 100 replicate models originally produced. The sum of these 10 models was taken as the best hypothesis of the species' distribution.

We inspected the distributional hypotheses for each species to establish a threshold for decisions of presence versus absence (lowest training presence threshold, Pearson et al. 2007). Initial model predictions in two cases (S. yunnanensis and S. nagaensis) were too broad and general and we used a tighter convergence criterion (convergence 0.001 ; maximum iterations 10,000), which resulted in closer correspondence between model predictions and known distributional limits. No tests of model quality were developed given uneven sample sizes across species and known ability of Ecological Niche Models (ENMs) to reconstruct the generalities of species' distributions at continental scales (Elith et al. 2006).

We related model predictions for each species to the original ecological variables on which the models were based to reconstruct models in ecological space. We used the 'Grid Combine' option in ArcGIS 9.0 to create a grid with a distinct value for all unique combinations of the environmental coverages across Eurasia. The attributes table associated with this grid yielded a matrix showing all unique environmental combinations and predictions associated with each species, which permitted several visualization exercises. Niche breadth was reconstructed as the variance of distributions in a standardized principal components analysis (Rotenberry and Wiens 1980, Carnes and Slade 1982, Litvak and Hansell 1990). Niche volume was calculated as the spatial translation of the niche in terms of areal coverage of the distribution across the landscape of interest without attention to which part is actually occupied by the species (Soberón 2007).

We established which portions of the potential distributional area are likely not to be inhabited to explore differences between actual and potential distributional areas (Svenning and Skov 2004). We were conservative and only eliminated as uninhabited those areas that were disjunct from areas of known occurrence, and from which no occurrences were known. These steps resulted in maps of the likely actual area of occurrence (Soberón and Peterson 2005). Proportional range occupancy was calculated as the ratio of the areas covered by the actual and potential distributional areas. We classed each species as occurring primarily in lowlands, foothills, or at high elevations based on published descriptions of nuthatch natural history (Matthysen 1998).

\section{RESULTS}

Niche Models. - These models produced realistic predicted distributions. For example, we used 17 available unique occurrence points for S. cashmirensis to characterize the species' distribution (Fig. 1). Initial results from the 


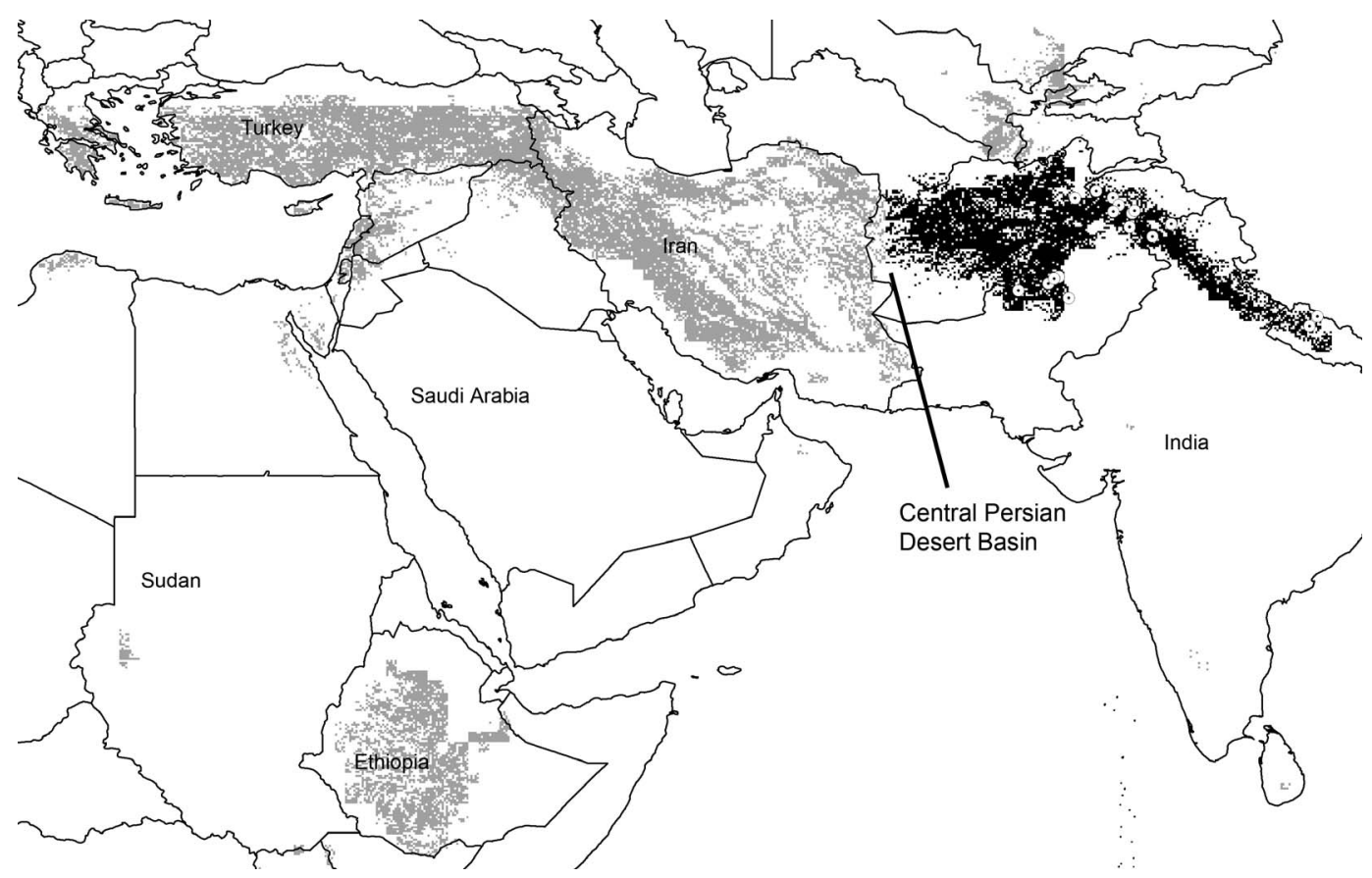

FIG. 1. Kashmir Nuthatch (Sitta cashmirensis) illustrating known occurrence points (dotted circles), crude potential geographic distribution (gray shading), and estimated actual distribution (black shading).

ENM algorithm identified mainly highland areas as potential distributional areas including the Himalayas of India, Nepal, and Pakistan (that constitute the known range of the species), as well as the highlands of Ethiopia and lower-elevation regions of Iran, Turkey, and Greece. A major disjunction in this distributional prediction corresponds to the dispersal barrier likely constraining this species to its present distribution: the Central Persian Desert Basin in central and eastern Iran, and western Afghanistan.

Geographic patterns of species richness based on the modeled distributions of nuthatch species were striking (Fig. 2). Spread generally across southern Asia, nuthatches show a dramatic richness focus in a narrow east-west band corresponding to the forested parts of the Himalayas, extending eastward into southwestern China (especially Szechuan and Yunnan provinces) and northern Burma. These foci reach predicted species richness up to nine species present (Fig. 2). However, the coarse resolution of our predictions $\left(0.17^{\circ}\right.$, or $\sim 18.9 \mathrm{~km}$ ) precludes separation of local species richness from high local-scale species turnover corresponding to local habitat diversity. These distributional predictions have a middle elevation focus (Fig. 3) with lowland areas and elevations above $\sim 3,000 \mathrm{~m}$ having relatively few species; intervening elevations $(1,000-2,000 \mathrm{~m})$, have the highest species diversity.

Niche Dimensions and Disequilibrium.The relationship between niche breadth and extent was positive (Fig. 4) because wide niche breadths tend to map onto large geographic areas, but accumulation of distributional area (niche volume) decreases with additional environmental combinations (niche breadth). Proportional range-filling indices showed a negative relationship with montane habit (Fig. 5). An outlier in this relationship was the White-browed Nuthatch; regressions including this species explained $10 \%$ of the overall variation $\left(R^{2}=0.102 ; P<0.05\right)$, whereas excluding it explained fourfold more variation $\left(R^{2}=0.422 ; P<0.05\right)$. The probable relictual nature of this species needs further investigation, but montane characteristics clearly limit the distributional potential of nuthatch species. 


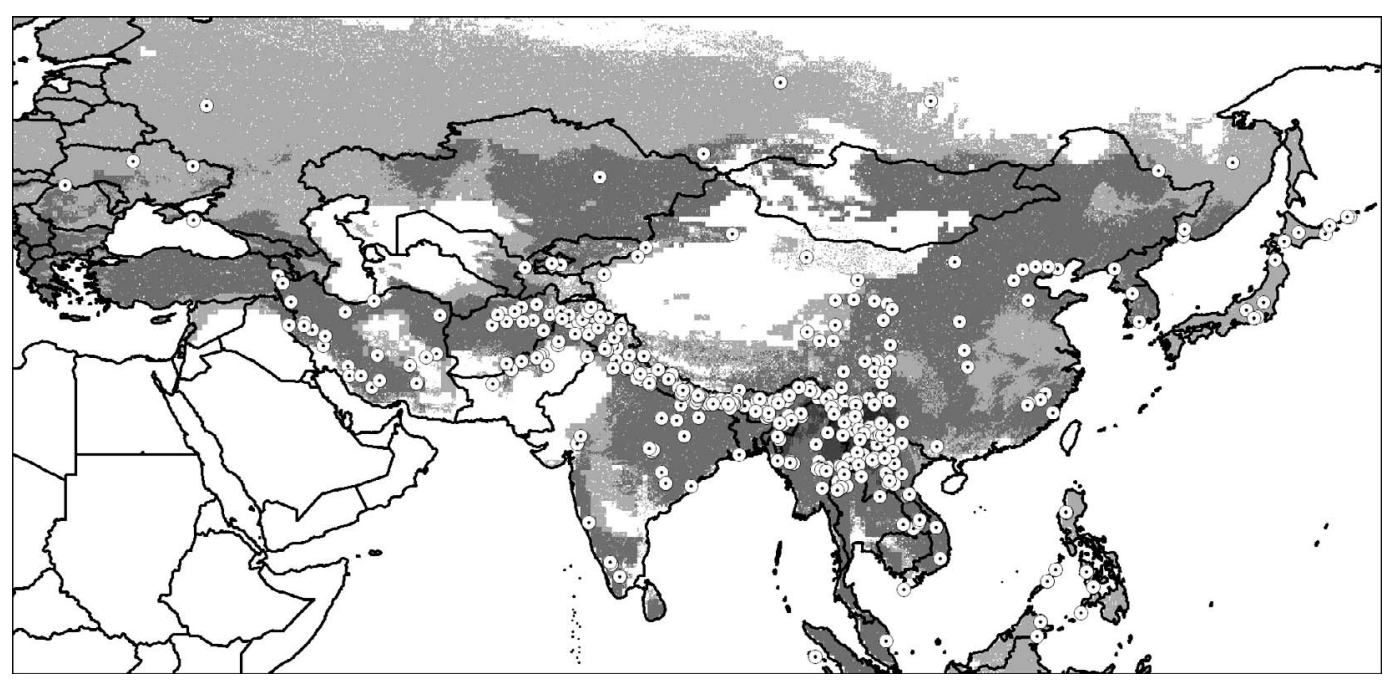

FIG. 2. Overall patterns of predicted species richness among Asian nuthatches (ramp from white $=0$ species predicted present, darkest gray $=9$ species predicted present). Sampling points (i.e., occurrence records for the 15 species in the study) are shown as dotted circles.

\section{DISCUSSION}

Niche breadth and volume represent two measures of the ecological niche amplitude of a species, the former in terms of ecological combinations and the latter reflecting the spatial manifestation (Soberón 2007). These quantities are only beginning to be characterized and few studies have explored their relationships. The positive niche breadth and volume relationship observed in this study is of interest and should be explored in additional groups.
Recent studies have explored the extent to which species fill their potential distributions, a measure of distributional disequilibrium (Svenning and Skov 2004). We generally found low proportional range filling among nuthatch species, particularly those with montane distributions. This suggests that nuthatch distributions will frequently be constrained by limited dispersal abilities.

Montane Ecology and Geography.-Nuthatch diversity patterns are related to the major mountain systems and associated cool tem-

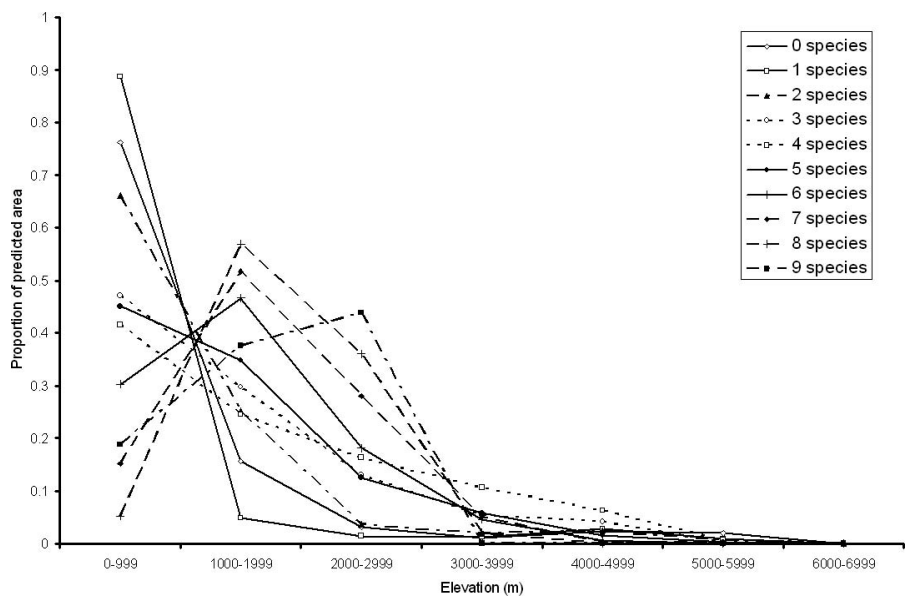

FIG. 3. Relationship between number of nuthatch species predicted present and elevation across Asia. 


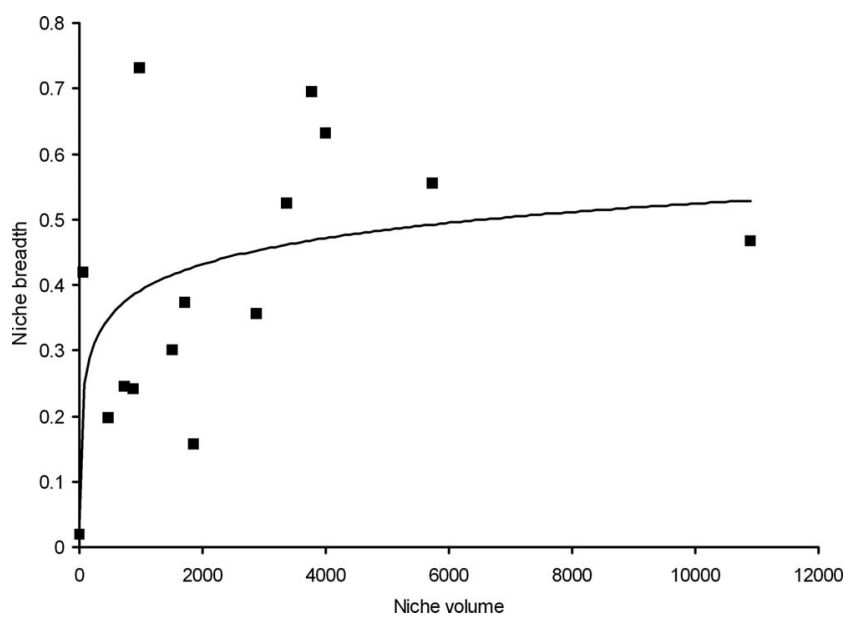

FIG. 4. Relationship between niche volume and niche breadth. Niche breadth is measured as the average variance across the uncorrelated principal components, whereas niche volume is the geographic projection (in $\mathrm{km}^{2}$ ) of the ecological niche model.

perate climates. Most nuthatch species have narrow geographic distributions in subtropical regions; those few with broader distributions range considerably farther and more broadly. The nuthatch diversity focus coincides closely with the Qinghai-Tibet Plateau region known to contain the largest concentration of Endemic Bird Areas in Asia (Long et al. 1996), as well as a focus of bird species richness (Ding et al. 2006). This association illustrates the seeming contradiction that most nuthatch species have small ranges, but the temperate-zone conditions they prefer are represented much more broadly farther to the north.
These results raise issues of biogeography and the role of geography in subdividing geographic distributions of evolving lineages. If species do not fill their ranges as completely in montane environments as in lowland environments, and if ecological niches are relatively conservative (Peterson et al. 1999), interactions may exist between geographic potential and ecological habit. Lowland species may have broader geographic distributions, but montane species may experience greater subdivision or have greater potential for isolation of populations that manage to colonize across dispersal barriers. Tests of these and

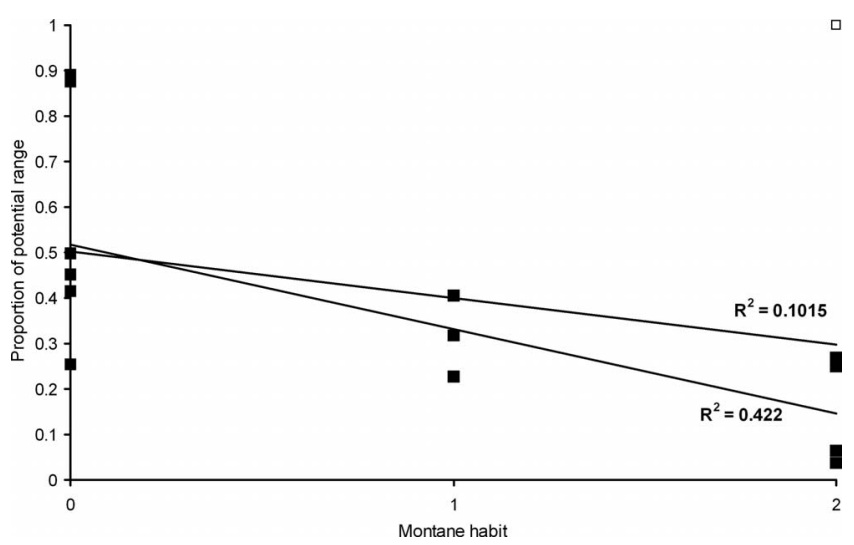

FIG. 5. Relationship between proportion of potential distribution actually occupied and montane habit $(0=$ lowlands, $1=$ foothills, $2=$ high elevations). Shown are two simple linear regressions, one including $\left(R^{2}=\right.$ $0.102)$ and the other excluding $\left(R^{2}=0.422\right)$ Sitta victoriae (open box). 
other hypotheses will be feasible once a robust phylogenetic hypothesis is available for the group.

\section{CONSERVATION IMPLICATIONS}

One fifth of all Asian nuthatch species are considered threatened (Collar et al. 1994, IUCN 2006). Among threatened Asian species, $S$. victoriae has an extremely narrow range, is listed as Endangered (IUCN 2006), and would clearly be threatened by any significant habitat destruction in the Mount Victoria region. Four other species ( $S$. solangiae, S. yunnanensis, S. formosa, S. magna) have wider ranges, but are threatened by habitat loss and degradation (Matthysen 1998, BirdLife International 2004, IUCN 2006). Sitta formosa and $S$. magna have small populations, which are thought to be declining and severely fragmented, and are listed as Vulnerable. Sitta solangiae and S. yunnanensis are affected by ongoing habitat loss and degradation, but have larger populations and are listed as near Threatened (IUCN 2006). The area of highest nuthatch species diversity, predicted by our analysis, closely matches the Sino-Himalayan Mountain Forest region identified by BirdLife International (2003) as one of nine key forest regions for threatened birds in Asia.

The Chinese and Himalayan region consists of middle- and high-elevation forests, scrub, and grasslands on the southern slopes of the Himalayas and in the mountains of southwestern China and northern Indochina. The natural habitat in this region is relatively secure at higher altitudes compared to middle elevations, which is under greater pressure from deforestation and fragmentation. Middleelevation forests are also the areas where our analysis predicts highest nuthatch species diversity. Habitat fragmentation further compounds the conservation implications for montane species, which have a greater potential for isolation. Our results emphasize the importance of middle-elevation habitats in this region for biodiversity.

\section{ACKNOWLEDGMENTS}

This research was supported by an NSF-Research Opportunity Award. We gratefully acknowledge Asad Rahmani (Director, Bombay Natural History Society) for support, Monica Papeş for technical assistance, and
Jill Witt for introducing the Beautiful Nuthatch (Sitta formosa) to the Menon Laboratory.

\section{LITERATURE CITED}

Anderson, R. P., D. Lew, And A. T. Peterson. 2003. Evaluating predictive models of species' distributions: criteria for selecting optimal models. Ecological Modelling 162:211-232.

Anderson, R. P., A. T. Peterson, AND M. Gómez-LAVERDE. 2002. Using niche-based GIS modeling to test geographic predictions of competitive exclusion and competitive release in South American pocket mice. Oikos 93:3-16.

BirdLIFE International. 2003. Saving Asia's threatened birds: a guide for government and civil society. Birdlife International, Cambridge, United Kingdom.

BIRDLIFE INTERNATIONAL. 2004. Threatened birds of the world 2004. CD-ROM. BirdLife International, Cambridge, United Kingdom.

Carnes, B. and N. Slade. 1982. Some comments on niche in canonical space. Ecology 63:888-893.

Chapman, A. D. AND J. WieczoreK (Editors). 2006. Guide to best practices for georeferencing. Global Biodiversity Information Facility, Copenhagen, Denmark. www.gbif.org/prog/digit/data_quality/ BioGeomancerGuide.pdf (accessed 10 August 2007).

Collar, N. J., M. J. Crosby, And A. J. Stattersfield. 1994. Birds to watch, 2. The world list of threatened birds. BirdLife Conservation Series Number 4. BirdLife International, Cambridge, United Kingdom.

Collar, N. J., A. V. Andreev, S. Chan, M. J. Crosby, S. Subramanya, and J. A. Tobias. 2001. Threatened birds of Asia: the BirdLife International Red Data Book. BirdLife International, Cambridge, United Kingdom.

Ding, T., H. Yuan, S. Geng, C. KoH, and P. Lee. 2006. Macro-scale bird species richness patterns of the East Asian mainland and islands: energy, area and isolation. Journal of Biogeography 33:683-693.

Elith, J., C. H. Graham, R. P. Anderson, M. Dudik, S. Ferrier, A. Guisan, R. J. Hijmans, F. Huettman, J. R. Leathwick, A. Lehmann, J. Li, L. G. Lohmann, B. A. Loiselle, G. Manion, C. MoRITZ, M. NAKAMURA, Y. NAKAZAWA, J. M. OVERton, A. T. Peterson, S. J. Phillips, K. RichardSon, R. Scachetti-Pereira, R. E. Schapire, J. Soberón, S. E. Williams, M. S. Wisz, and N. E. ZimMERMANN. 2006. Novel methods improve prediction of species' distributions from occurrence data. Ecography 29:129-151.

Graham, C. H., S. Ferrier, F. Huettman, C. Moritz, And A. T. Peterson. 2004. New developments in museum-based informatics and applications in biodiversity analysis. Trends in Ecology and Evolution 19:497-503.

GRINNELL, J. 1917. Field tests of theories concerning distributional control. American Naturalist 51: $115-128$. 
HarRaP, S. AND D. QuinN. 1995. Chickadees, tits, nuthatches and treecreepers. Princeton University Press, Princeton, New Jersey, USA.

Hijmans, R. J., S. Cameron, and J. Parra. 2005. WorldClim. Version 1.3. University of California, Berkeley, USA. http://biogeo.berkeley.edu/ worldclim/worldclim.htm (accessed 10 August 2007).

Illoldi, P., V. SÁnchez-Cordero, AND A. T. Peterson. 2004. Predicting distributions of Mexican mammals using ecological niche modeling. Journal of Mammalogy 85:658-662.

IUCN 2006. 2006 IUCN Red List of threatened species. http://www.iucnredlist.org (accessed $10 \mathrm{Au}-$ gust 2007).

LACK, D. 1971. Ecological isolation in birds. Harvard University Press, Cambridge, Massachusetts, USA.

LitvaK, M. AND R. I. Hansell. 1990. A community perspective on the multidimensional niche. Journal of Animal Ecology 59:931-940.

Long, A. J., M. J. Crosby, ANd A. J. SAtTersfield. 1996. Towards a global map of biodiversity: patterns in the distribution of restricted-range birds. Global Ecology and Biogeography Letters 5:281304.

Martínez-Meyer, E., A. T. Peterson, ANd W. W. HarGROVE. 2004. Ecological niches as stable distributional constraints on mammal species, with implications for Pleistocene extinctions and climate change projections for biodiversity. Global Ecology and Biogeography 13:305-314.

Matthysen, E. 1998. The nuthatches. T. and A. D. Poyser, London, United Kingdom.

MAYR, E. AND D. Amadon. 1951. A classification of recent birds. American Museum Novitates 1946: 453-473.

National Geospatial Intelligence Agency. 2007. GEOnet Names Server (GNS). http://earthinfo.nga.mil/gns/html/index.html (accessed 10 August 2007).

Ortega-Huerta, M. A. And A. T. Peterson. 2004. Modeling spatial patterns of biodiversity in northeastern Mexico. Diversity and Distributions 10: $39-54$.

Pearson, R. G., C. Raxworthy, M. Nakamura, and A. T. Peterson. 2007. Predicting species' distributions from small numbers of occurrence records: a test case using cryptic geckos in Madagascar. Journal of Biogeography 34:102-117.

Peterson, A. T. 2003. Predicting the geography of species' invasions via ecological niche modeling. Quarterly Review of Biology 78:419-433.

Peterson, A. T. 2005. Kansas Gap Analysis: the importance of validating distributional models before using them. Southwestern Naturalist 50:230-236.

Peterson, A. T. And K. C. Cohoon. 1999. Sensitivity of distributional prediction algorithms to geo- graphic data completeness. Ecological Modelling 117:159-164.

Peterson, A. T. and R. D. Holt. 2003. Niche differentiation in Mexican birds: using point occurrences to detect ecological innovation. Ecology Letters 6:774-782.

Peterson, A. T., J. Soberón, And V. SÁnchez-CorDERO. 1999. Conservatism of ecological niches in evolutionary time. Science 285:1265-1267.

Peterson, A. T., R. R. Lash, D. S. Carroll, and K. M. JoHnson. 2006. Geographic potential for outbreaks of Marburg hemorrhagic fever. American Journal of Tropical Medicine and Hygiene 75:915.

RIPLEY, S. D. 1959. Character displacement in Indian nuthatches (Sitta). Postilla 42:1-11.

Rotenberry, J. T. AND J. A. WIENS. 1980. Habitat structure, patchiness, and avian communities in North American steppe vegetation: a multivariate analysis. Ecology 61:1228-1250.

Sibley, C. G. AND J. E. Ahlquist. 1990. Phylogeny and classification of birds: a study in molecular evolution. Yale University Press, New Haven, Connecticut, USA.

SOBERón, J. 2007. Grinnellian and Eltonian niches and geographic distributions of species. Ecology Letters 10:1115-1123.

Soberón, J. And A. T. Peterson. 2004. Biodiversity informatics: managing and applying primary biodiversity data. Philosophical Transactions of the Royal Society of London, Series B 359:689-698.

Soberón, J. AND A. T. Peterson. 2005. Interpretation of models of fundamental ecological niches and species' distributional areas. Biodiversity Informatics 2:1-10.

Stockwell, D. R. B. and D. P. Peters. 1999. The GARP modeling system: problems and solutions to automated spatial prediction. International Journal of Geographical Information Science 13:143158.

Stockwell, D. R. B. And A. T. Peterson. 2002a. Controlling bias in biodiversity data. Pages 537-546 in Predicting species occurrences: issues of scale and accuracy (J. M. Scott, P. J. Heglund, and M. L. Morrison, Editors). Island Press, Washington, D.C., USA.

Stockwell, D. R. B. and A. T. Peterson. 2002b. Effects of sample size on accuracy of species distribution models. Ecological Modelling 148:1-13.

Stockwell, D. R. B. AND A. T. Peterson. 2003. Comparison of resolution of methods used in mapping biodiversity patterns from point occurrence data. Ecological Indicators 3:213-221.

SVEnNing, J.-C. AND F. SKov. 2004. Limited filling of the potential range in European tree species. Ecology Letters 7:565-573.

U.S. Department of InTERIOR (USDI). 2001. Hydro$1 \mathrm{~K}$ elevation derivative data base. USDI, Geological Survey, Washington, D.C., USA. http:// edcdaac.usgs.gov/gtopo30/hydro/ (accessed 10 August 2007). 